\title{
Relationship between Mucoid Degeneration of the Anterior Cruciate Ligament and Posterior Tibial Slope in Patients with Total Knee Arthroplasty
}

\author{
Yoon-Seok Youm, MD, Sung-Do Cho, MD, Hye-Yong Cho, MD, and Seung-Hyun Jung, MD \\ Department of Orthopedic Surgery, Ulsan University Hospital, Ulsan, Korea
}

\begin{abstract}
Purpose: The purpose was to analyze the relationship between posterior tibial slope (PTS) and mucoid degeneration of the anterior cruciate ligament (ACL) in patients with total knee arthroplasty.

Materials and Methods: Four hundred and twenty-four patients (24 males and 400 females; 636 knees) who received total knee arthroplasty for osteoarthritis were included. Their mean age was 68.9 years (range, 48 to 88 years). The patients were classified into three groups according to the status of ACL; normal ACL group (group I), mucoid degeneration of ACL group (group II) and ruptured or absent ACL group (group III). Plain lateral radiographs were used to measure the PTS and the values were compared among groups.

Results: There were no significant differences with regard to gender, age and left-to-right side ratio among groups (p $>0.05)$. The mean PTS was 9.9 ${ }^{\circ}$ (range, $0.6^{\circ}$ to $20.1^{\circ}$ ) in group I (161 knees), $10.8^{\circ}$ (range, $0.2^{\circ}$ to $21.8^{\circ}$ ) in group II (342 knees) and $12.3^{\circ}$ (range, $2^{\circ}$ to $22.2^{\circ}$ ) in group III $(133$ knees), which showed significant differences $(\mathrm{p}<0.001)$.

Conclusions: The patients with mucoid degeneration of the ACL and those with ruptured or absent ACL had greater PTS than those with normal ACL. These findings suggest that an increased PTS may be one of the causative factors for mucoid degeneration of the ACL.
\end{abstract}

Keywords: Knee, Arthroplasty, Posterior tibial slope, Anterior cruciate ligament, Mucoid degeneration

\section{Introduction}

Mucoid degeneration of the anterior cruciate ligament (ACL) has been implicated as one of the factors responsible for knee pain $^{1-8)}$. Kumar et al. ${ }^{3)}$ first documented a case of biopsy indicated ACL mucoid degeneration in 1999. Contrary to the previous reports of the rarity of the lesion, recent studies have revealed relatively high prevalence ${ }^{9-12)}$. Etiological factors of mucoid degeneration of the ACL include repeated trauma to the ACL or degeneration of the ligament, chronic impingement of the ACL,

Received July 27, 2015; Accepted September 9, 2015

Correspondence to: Sung-Do Cho, MD

Department of Orthopedic Surgery, Ulsan University Hospital, 877

Bangeojinsunhwan-doro, Dong-gu, Ulsan 44033, Korea

Tel: +82-52-250-7129, Fax: +82-52-235-2823

E-mail: sdcho@uuh.ulsan.kr

This is an Open Access article distributed under the terms of the Creative Commons Attribution Non-Commercial License (http://creativecommons.org/licenses/by-nc/4.0/) which permits unrestricted non-commercial use, distribution, and reproduction in any medium, provided the original work is properly cited. synovial changes, and influence of anatomical variables such as the intercondylar notch of the knee and posterior tibial slope $(\mathrm{PTS})^{9,10,13-17)}$. In general, conservative treatment is the initial treatment of choice; however, if symptoms do not improve, arthroscopic partial resection of the ACL can be performed ${ }^{11,18-20)}$.

PTS is anatomically associated with anterior tibial translation, and it is positively correlated with anterior tibial translation, resulting in increased load on the $\mathrm{ACL}^{21,22)}$. Studies have suggested there is a relationship between PTS and mucoid degeneration of the ACL and increased posterior slope has been associated with increased risk of ACL injury ${ }^{16,17,23,24)}$.

The purpose of the current study was to investigate the relationship between mucoid degeneration of the ACL identified during total knee arthroplasty (TKA) and PTS.

\section{Materials and Methods}

This study was conducted on a total of 424 patients ( 636 knees) who underwent TKA under the diagnosis of Kellgren-Lawrence 
grade IV osteoarthritis of the knee between May 2007 and February 2011. There were 24 males and 400 females with a mean age of 68.9 years (range, 48 to 88 years). The exclusion criteria were previous surgery on the ipsilateral knee, lower limb deformity, mediolateral ligament instability, revision TKA, and rheumatoid arthritis.

The surgery was performed by the same surgeon (Cho SD) in all patients with a standard midline skin incision and a medial parapatellar approach. Intraoperatively, the presence of ACL degeneration/tear was identified and recorded by the same surgeon (Cho SD). Specimens obtained during surgery were histopathologically reviewed. The ultimate diagnosis of ACL mucoid degeneration was based on the gross observation and histopathological findings. According to the diagnostic results, the patients were divided into three groups: group I, patients with normal ACL; group II, patients with mucoid degeneration of ACL; and group III, patients with ruptured or absent ACL (Fig. 1).

PTS was assessed on the lateral radiograph using the picture archiving communication system (PiView STAR software; Infinitt, Seoul, Korea) by an orthopedist who was blinded to patient data. For the measurement of PTS, the diaphyseal axis of the tibia was established as a line connecting the two points equidistant from the anterior and posterior borders of the tibia, one was immediately inferior to the tibial tubercle and the other was $10 \mathrm{~cm}$ more distal to it. A reference line was drawn perpendicular to the diaphyseal axis at the level of the femorotibial joint. Then, another line was drawn by connecting the highest points of the anterior and posterior edges of the medial plateau. The angle between this line and the reference line was defined as the PTS (Fig. 2).

Statistical analysis was performed to determine statistical significance of difference in PTS among groups. A chi-square test was used to compare demographic characteristics among groups, and PTS was compared using the one-way analysis of variance test. The relationship between age and PTS in each group was as- sessed using the Pearson correlation test. For statistical analysis, SPSS ver. 21.0 (IBM Co., Armonk, NY, US) was used with the significance level set at $\mathrm{p}<0.05$.

\section{Results}

Of the total 636 knees, ACL degeneration or tear was not observed in 161 knees (25.3\%, group I), mucoid degeneration was observed in 341 knees (53.6\%, group II), and the ACL was either ruptured or absent in 133 knees (20.9\%, group III). There was no statistically significant difference among the groups with regard to gender, age, and the left-to-right side ratio ( $p>0.05)$ (Table 1).

The mean PTS was $9.9^{\circ}$ (range, $0.6^{\circ}$ to $20.1^{\circ}$ ) in group I, $10.8^{\circ}$ (range, $0.2^{\circ}$ to $21.8^{\circ}$ ) in group II, and $12.3^{\circ}$ (range, $2^{\circ}$ to $22.2^{\circ}$ ) in group III, showing statistically significant difference among groups $(\mathrm{p}<0.001)$ (Table 2$)$.

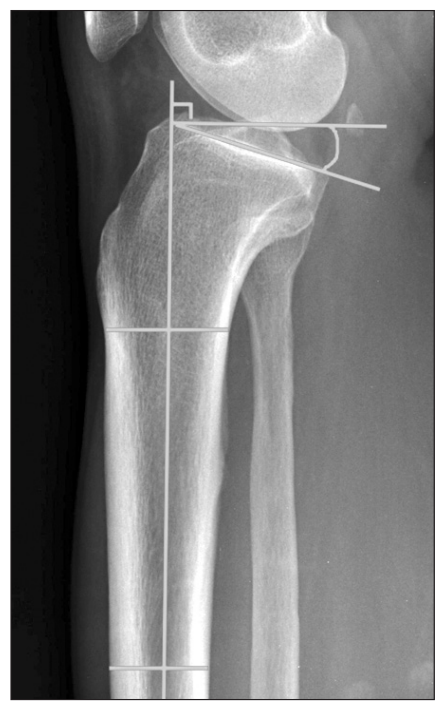

Fig. 2. Posterior tibial slope measurement.
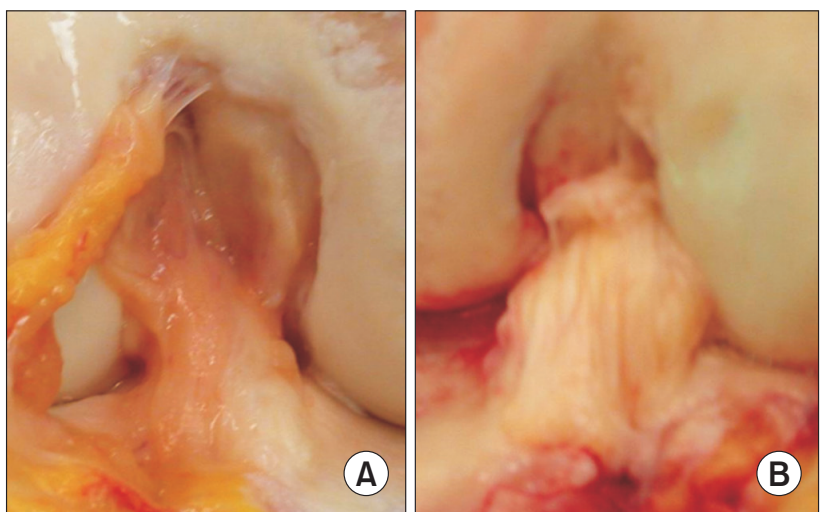

Fig. 1. Intraoperative gross appearance of the anterior cruciate ligament (ACL). Normal (A), mucoid degeneration (B), and rupture or absence $(\mathrm{C})$ of the ACL. 
Due to the comparatively low proportion of males in each group, statistical analysis of male-to-female comparison of PTS could not be carried out. Age was found to have no influence on PTS ( $>>0.05)$.

\section{Discussion}

The results of the current study showed increased PTS in the knees with mucoid degeneration of the ACL or those with rupture or absence of the ligament compared to those with normal ACL.

Mucoid degeneration of the ACL can be diagnosed based on magnetic resonance imaging (MRI) findings, gross observations, and histopathological examinations. MRI characteristics of ACL mucoid degeneration include ill-defined and thickened ligament, increased signal intensity and celery stalk sign, and intraoperative

Table 1. Demographics

\begin{tabular}{lrcc}
\hline Variable & Group I & Group II & Group III \\
\hline Age $(\mathrm{yr})$ & $67.6 \pm 6.7$ & $68.8 \pm 7.1$ & $69.4 \pm 6.7$ \\
Gender & & & \\
Male & 5 & 20 & 7 \\
Female & 156 & 322 & 126 \\
Side & & & \\
Right & 86 & 176 & 63 \\
Left & 75 & 166 & 70
\end{tabular}

Values are presented as mean \pm standard deviation or number. findings include ACL thickening, discharge of mucoid materials or loss of synovial lining, and impingement in full extension of the knee ${ }^{4,9,25,26)}$. Histopatholoigcal indications are increased collagen production and alterations in mucoid materials ${ }^{17,25}$. In our study, intraoperative gross findings and histopathological examinations were used for the assessment of mucoid degeneration of the ACL, and MRI was not carried out.

PTS is measured as the angle between a line perpendicular to the mid-diaphysis of the tibia and a line parallel to posterior tibial inclination. A normal PTS ranges from $7^{\circ}$ to $13^{\circ}$ although some variations exist depending on the measurement site and meth$\mathrm{od}^{27)}$. Besides, the values on plain radiographs tend to be greater than those on MRI images ${ }^{28}$. PTS is positively correlated with anterior tibial translation ${ }^{21,22)}$. Based on a review of cadaveric studies and mathematical models, Feucht et al. ${ }^{27)}$ concluded that PTS was positively correlated with anterior translation of the tibia; however, the influence of anterior tibial shift on increased strain in the ACL could be confirmed only in mathematical models, not in cadaveric studies. In spite of this, they conjectured that a steep tibial posterior slope is a risk factor for ACL injuries. Some studies have shown that PTS is greater in the ACL tear group than in the normal ACL group. Similarly, increased PTS was found to be associated with ACL injuries in a multitude of studies ${ }^{14,16,24,29)}$.

Table 2. Posterior Tibial Slope (PTS)

\begin{tabular}{cccc}
\hline & Group I & Group II & Group III \\
\hline PTS $\left(^{\circ}\right)$ & $9.9 \pm 3.4(0.6-20.1)$ & $10.8 \pm 3.5(0.2-21.8)$ & $12.3 \pm 4.3(2.0-22.2)$ \\
\hline
\end{tabular}

Values are presented as mean \pm standard deviation (range).
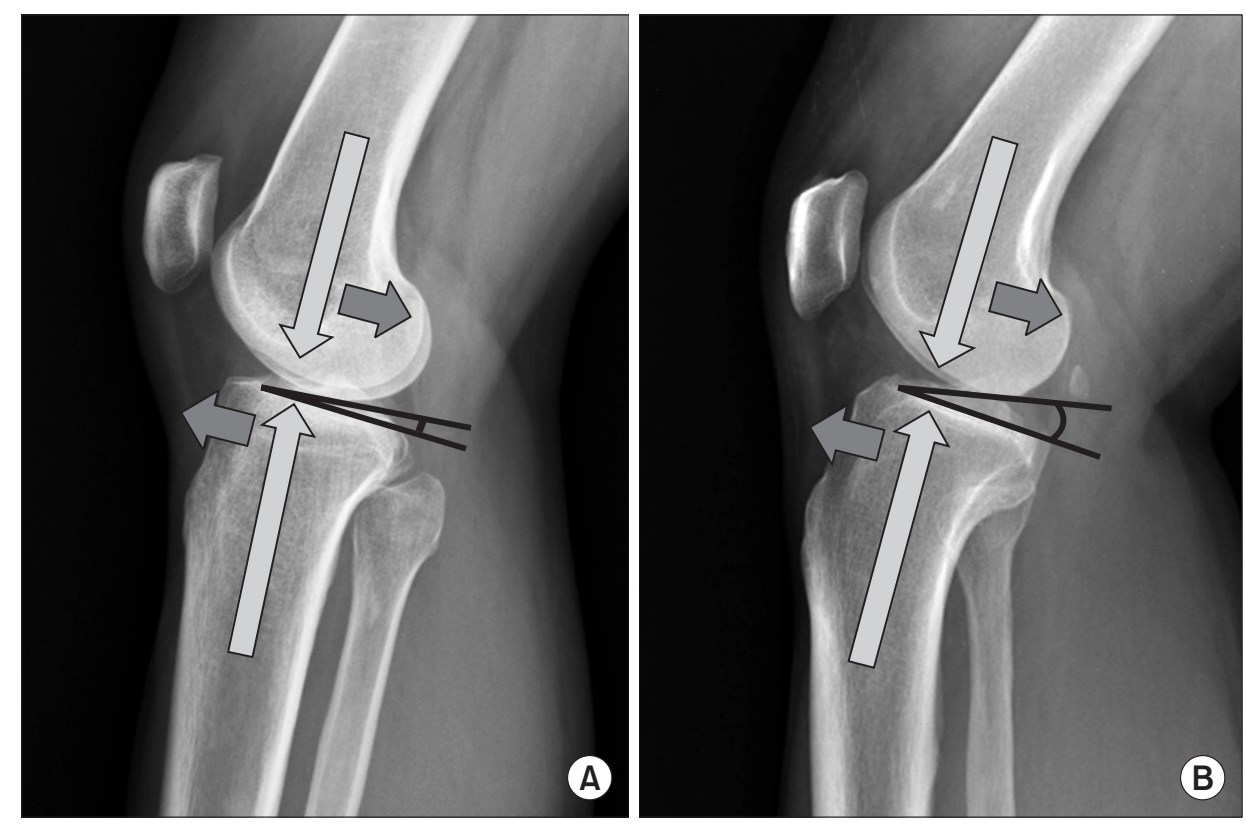

Fig. 3. (A) Relationship between posterior tibial slope (PTS) and anterior tibial translation. (B) Increased PTS may cause increased anterior tibial translation. 
Based on the review of the abovementioned studies, we assumed a positive correlation between PTS and anterior translation of the tibia, which predisposes the ACL to biomechanical alterations resulting in constant damage to the ACL and mucoid degeneration (Fig. 3). Jung et al. ${ }^{17}$ reported that PTS was significantly greater in the patient group with mucoid degeneration than in the control group. In our study, increased PTS was observed in the mucoid degeneration group (group II) and absent or torn ACL group (group III) compared to the normal ACL group (group I). In addition, the PTS was significantly greater in group III than in group II, suggesting that mucoid degeneration can eventually progress to a tear or loss of the ACL. Therefore, in the absence of clear understanding of the mechanism, we surmise there is a relatively close relationship between PTS and mucoid degeneration of the ACL. It is our understanding that the possibility of ACL injury or mucoid degeneration should be taken into consideration if a steep PTS is observed during clinical examination.

We acknowledge there are some limitations or our study. First, the influence of meniscus on the PTS was not addressed in the analysis because measurements were performed using plain radiographs. Second, other factors that could affect mucoid degeneration were not investigated. Third, we did not attempt to identify the exact mechanism of mucoid degeneration.

\section{Conclusions}

The patients with mucoid degeneration of the ACL and those with ruptured or absent ACL had greater PTS than those with normal ACL. These findings suggest that an increased PTS may be one of the causative factors for mucoid degeneration of the ACL.

\section{Conflict of Interest}

No potential conflict of interest relevant to this article was reported.

\section{References}

1. Fealy S, Kenter K, Dines JS, Warren RF. Mucoid degeneration of the anterior cruciate ligament. Arthroscopy. 2001;17: E37.

2. Hsu CJ, Wang SC, Fong YC, Huang CY, Chiang IP, Hsu HC. Mucoid degeneration of the anterior cruciate ligament. J Chin Med Assoc. 2006;69:449-52.
3. Kumar A, Bickerstaff DR, Grimwood JS, Suvarna SK. Mucoid cystic degeneration of the cruciate ligament. J Bone Joint Surg Br. 1999;81:304-5.

4. McIntyre J, Moelleken S, Tirman P. Mucoid degeneration of the anterior cruciate ligament mistaken for ligamentous tears. Skeletal Radiol. 2001;30:312-5.

5. Melloni P, Valls R, Yuguero M, Sáez A. Mucoid degeneration of the anterior cruciate ligament with erosion of the lateral femoral condyle. Skeletal Radiol. 2004;33:359-62.

6. Motmans R, Verheyden F. Mucoid degeneration of the anterior cruciate ligament. Knee Surg Sports Traumatol Arthrosc. 2009;17:737-40.

7. Narvekar A, Gajjar S. Mucoid degeneration of the anterior cruciate ligament. Arthroscopy. 2004;20:141-6.

8. Nishimori M, Sumen Y, Sakaridani K. Mucoid degeneration of the anterior cruciate ligament: a report of two cases. Magn Reson Imaging. 2004;22:1325-8.

9. Kim TH, Lee DH, Lee SH, Kim JM, Kim CW, Bin SI. Arthroscopic treatment of mucoid hypertrophy of the anterior cruciate ligament. Arthroscopy. 2008;24:642-9.

10. Kwee RM, Ahlawat S, Kompel AJ, Morelli JN, Fayad LM, Zikria BA, Demehri S. Association of mucoid degeneration of anterior cruciate ligament with knee meniscal and cartilage damage. Osteoarthritis Cartilage. 2015;23:1543-50.

11. Cha JR, Lee CC, Cho SD, Youm YS, Jung KH. Symptomatic mucoid degeneration of the anterior cruciate ligament. Knee Surg Sports Traumatol Arthrosc. 2013;21:658-63.

12. Salvati F, Rossi F, Limbucci N, Pistoia ML, Barile A, Masciocchi C. Mucoid metaplastic-degeneration of anterior cruciate ligament. J Sports Med Phys Fitness. 2008;48:483-7.

13. Cha JH, Lee SH, Shin MJ, Choi BK, Bin SI. Relationship between mucoid hypertrophy of the anterior cruciate ligament (ACL) and morphologic change of the intercondylar notch: MRI and arthroscopy correlation. Skeletal Radiol. 2008;37: 821-6.

14. Diard F, Chateil JF, Hauger O, Moinard M. Para-articular and intraosseous synovial cysts and articular mucoid cysts. J Radiol. 1999;80(6 Suppl):679-96.

15. Rolf C, Watson TP. Case report: intra-tendinous ganglion of the anterior cruciate ligament in a young footballer. J Orthop Surg Res. 2006;1:11.

16. Sonnery-Cottet B, Archbold P, Cucurulo T, Fayard JM, Bortolletto J, Thaunat M, Prost T, Chambat P. The influence of the tibial slope and the size of the intercondylar notch on rupture of the anterior cruciate ligament. J Bone Joint Surg Br. 2011;93:1475-8. 
17. Jung KH, Cho SD, Park KB, Youm YS. Relation between mucoid degeneration of the anterior cruciate ligament and posterior tibial slope. Arthroscopy. 2012;28:502-6.

18. Morice A, Coupry A, Lintz F, Robert H. Reduction plasty for hypertrophic anterior cruciate ligament mucoid degeneration: clinical and knee laxity outcomes in 23 cases. Orthop Traumatol Surg Res. 2013;99:693-7.

19. Chudasama CH, Chudasama VC, Prabhakar MM. Arthroscopic management of mucoid degeneration of anterior cruciate ligament. Indian J Orthop. 2012;46:561-5.

20. Lintz F, Pujol N, Dejour D, Boisrenoult P, Beaufils P. Anterior cruciate ligament mucoid degeneration: selecting the best treatment option. Orthop Traumatol Surg Res. 2010;96:400-6.

21. Dejour H, Bonnin M. Tibial translation after anterior cruciate ligament rupture: two radiological tests compared. J Bone Joint Surg Br. 1994;76:745-9.

22. Giffin JR, Vogrin TM, Zantop T, Woo SL, Harner CD. Effects of increasing tibial slope on the biomechanics of the knee. Am J Sports Med. 2004;32:376-82.

23. Brandon ML, Haynes PT, Bonamo JR, Flynn MI, Barrett GR, Sherman MF. The association between posterior-inferior tibial slope and anterior cruciate ligament insufficiency. Arthroscopy. 2006;22:894-9.
24. Zeng C, Cheng L, Wei J, Gao SG, Yang TB, Luo W, Li YS, Xu $\mathrm{M}$, Lei GH. The influence of the tibial plateau slopes on injury of the anterior cruciate ligament: a meta-analysis. Knee Surg Sports Traumatol Arthrosc. 2014;22:53-65.

25. Makino A, Pascual-Garrido C, Rolon A, Isola M, Muscolo DL. Mucoid degeneration of the anterior cruciate ligament: MRI, clinical, intraoperative, and histological findings. Knee Surg Sports Traumatol Arthrosc. 2011;19:408-11.

26. Lintz F, Pujol N, Boisrenoult P, Bargoin K, Beaufils P, Dejour D. Anterior cruciate ligament mucoid degeneration: a review of the literature and management guidelines. Knee Surg Sports Traumatol Arthrosc. 2011;19:1326-33.

27. Feucht MJ, Mauro CS, Brucker PU, Imhoff AB, Hinterwimmer S. The role of the tibial slope in sustaining and treating anterior cruciate ligament injuries. Knee Surg Sports Traumatol Arthrosc. 2013;21:134-45.

28. Hudek R, Schmutz S, Regenfelder F, Fuchs B, Koch PP. Novel measurement technique of the tibial slope on conventional MRI. Clin Orthop Relat Res. 2009;467:2066-72.

29. Todd MS, Lalliss S, Garcia E, DeBerardino TM, Cameron KL. The relationship between posterior tibial slope and anterior cruciate ligament injuries. Am J Sports Med. 2010;38:63-7. 